\title{
Study on Conditions for Coalbed Methane Accumulation in Hegang Basin
}

\author{
Hu Hui ${ }^{1, a}$ \\ ${ }^{1}$ The First Mud Logging Company, Daqing Drilling \& Exploration Engineering Cooperation, China;
}

Ahuhui123@163.com

Keywords: Hegang basin, coalbed methane, conditions for coalbed methane accumulation

\begin{abstract}
The degree of metamorphism of coal seams in Hegang basin is mainly to medium coal rank. The macrolithotype of coal is rather excellent., given priority to half light type. In addition, there are a great number of thick coal seams in Hegang basin and the average thickness of the major coal seam can be more than $10 \mathrm{~m}$. Furthermore its gas content is high, and it is superior in quality of coalbed methane and conditions for Generating coalbed methane. However the permeability of the reservoir changes a lot, the lithology is unfavourable in top and bottom of reservoir which is exactly in favor of local caprock sealing ability. There are two main differences in north and south of the basin, the coal rank and the preservation conditions. The coal rank and permeability of north is high, and it has developed favorable caprock. In contrary, the coal rank in south is low and it hasn't buried deeply enough. It also lack favorable caprock. Based on Comprehensive analysis on these factors, the conditions for coalbed methane accumulation is superior to the south. It is better to explore the north of Hegang basin firstly.
\end{abstract}

\section{Introduction}

Hegang coal field is located in the northeast of Helongjiang Province, which is $6 \mathrm{~km}$ from east to west and $42 \mathrm{~km}$ from north to south. It has an area of 2800 square metres[1] with $48.12 \times 108 \mathrm{t}$ of coal resources and $631 \times 108 \mathrm{~m}^{3}$ predicted coalbed methane[2], and its abundance of resources is $1.5 \mathrm{~m} 3 / \mathrm{km}^{2}[3]$ 。 The coalbed methane in Hegang coal field has been explored for 13 years, but there is no remarkable progress. Only Nanshan mining area has been produced formally of nine mines in this basin currently, whose annual coalbed methane output is $0.2 \times 108 \mathrm{~m}^{3}$ [4]. Hence one can see that there is great potential in coalbed methane of Hegang basin. But the unclear conditions for coalbed methane accumulation has seriously prevented the exploration of coalbed methane in Hegang basin. Therefore, we analyse the conditions for coalbed methane accumulation from many factors, such as characteristics of coal seams, coal, coal reservoir and the preservation conditions to choos the prospective target area for coabed methane exploration and production.

\section{Characteristics of coal seams}

Hegang basin is a monoclinal structure with north-south trend, Strike direction of N25E and dip between $10^{\circ} \sim 35^{\circ}$ (Fig 1). The structure is complex and developed large and medium-sized fault in this area where developed 91 faults with over $100 \mathrm{~m}$ fault throw. However its hydrogeological conditions are simple, besides the connection between coal seam and hydraulic power in overlying aquifers and coal internal aquifers is weak. So it is favorable to exploration and development of coalbed methane. 


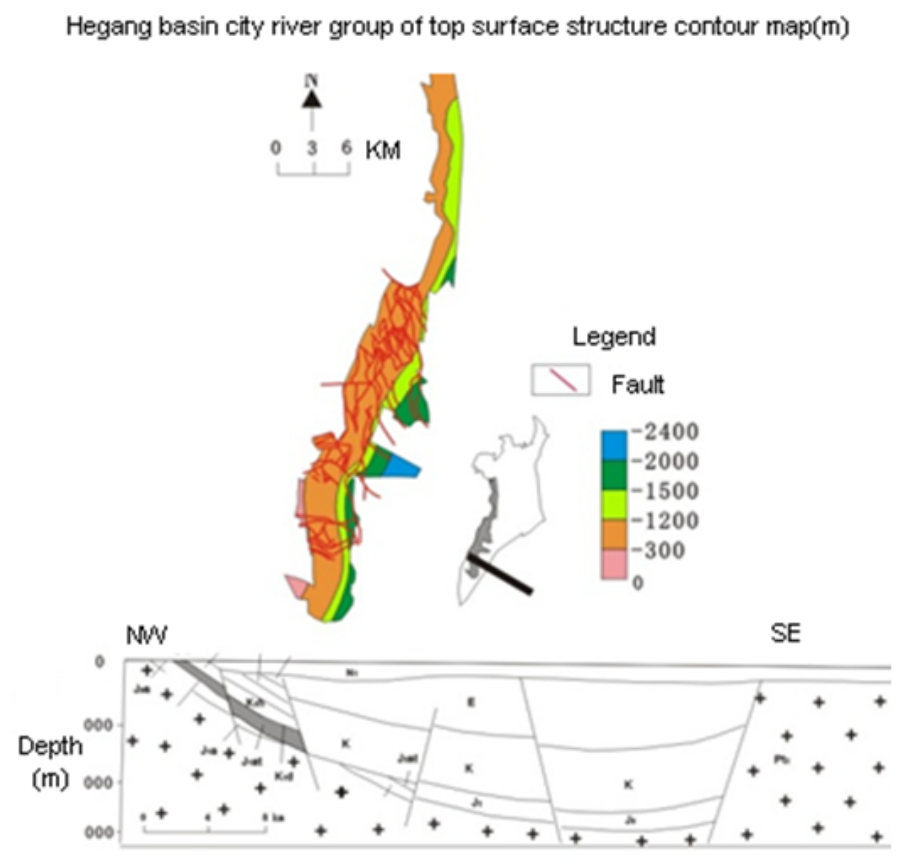

Fig. 1 Structure Contour map of strata Chengzihe upper surface in Hegang basin

The total thickness of strata Chengzihe formation is $700 \sim 1310 \mathrm{~m}$, containing a total of over 40 coal layers, including 36 exploiting and locally exploiting layers. The coal cumulative thickness is between $30 \sim 70 \mathrm{~m}$, of which most are thick and medium thick coal layers and a few are especially thick. Strata Muleng covered on the strata Chengzihe, whose total thickness is 600 955 m, containing 5 18 thin coal layers, including 4 5 exploiting layers, conformablly contacting with strata Chengzihe[4].

The coal seams in Hegang mining area is mainly distributed in $1500 \mathrm{~m}$ under ground, We always exploit in $900 \mathrm{~m}$ underground at present. The degree of metamorphism of coal in this area is mainly gas coal and fat coal, and its Ro is 0.65 1.7[4]. The coal seams in Hegang basin is the result of plutonic metamorphism and contact metamorphism. Along with the increase of longitudinal deepness, arising a plurality of Coal accumulation center(coal-forming center) laterally. Part of coal seams are affected by contact metamorphism due to the magmatic intrusion in Yanshanian, forming a series of coal seams of hige coal ranks and resulting in the difference between different coal ranks.

\section{Characteristics of coal}

The coal macrolithotype in Hegang mining area is given priority to half light type, then the semidull coal and bright coal. Because of being consist of bright coal, semidull coal, anthraxylous coal and charcoal like coal, the coal is thin banded or medium banded structure. The micropetrological unit of coal is mainly vitrinite, whose content is $52.2 \% \sim 82.3 \%$, then the semivitrinite content is $2.3 \% \sim 26.3 \%$, and the exinite content is $0.2 \% \sim 6.2 \%$ [4]. In addition, its ash content is high to $15 \sim 30 \%[5]$.

\section{Characteristics of coal reservoir}

The gas content between $500 \sim 1500 \mathrm{~m}$ in Hegang mining area is $1.6 \sim 19 \mathrm{~m}^{3} / \mathrm{t}$ and is high to $8.14 \sim 15.4 \mathrm{~m}^{3} / \mathrm{t}$ in Nanshan and Xinyi mine area[4]. The coalbed methane here has rather high quality with $\mathrm{CH}_{4}$ concentration high to $95 \% \sim 98 \%$. The permeability is commonly between $0.055 \mathrm{mD}$ and $0.382 \mathrm{mD}$. There is large difference in permeability in different mining area, presenting a trend of low in southwest and high in northeast. This pattern is the common effect of magmatic activity and tectonic movement. Exogenic crack developed well in this coal area, with crack density 2 20/10 $\mathrm{cm}^{[5]}$. 


\section{Preservation conditions}

Coal measures in Hegang coal field is continental sedimentation, most of whose roof is fine sandstone, only a few is sandy shale or medium sand and farewell rock. In addition, most of its base plate is sandstone, few is medium sand or silt. Thick, densify and siliceous cemented conglomerate in Nanling is favorable local cap rock for its excellent sealing ability [6]. According to statistic single well data in Hegang basin, we can see that the conditions for developing top cap bottom partition sealing type make up $42 \%$ of the total(Fig 2). Moreover, the basin is an asymmetric monoclinal structure, with weak hydrodynamic conditions, for which it is easy to form unidirectional hydropower blockage, so that it can preserve the coalbed methane.

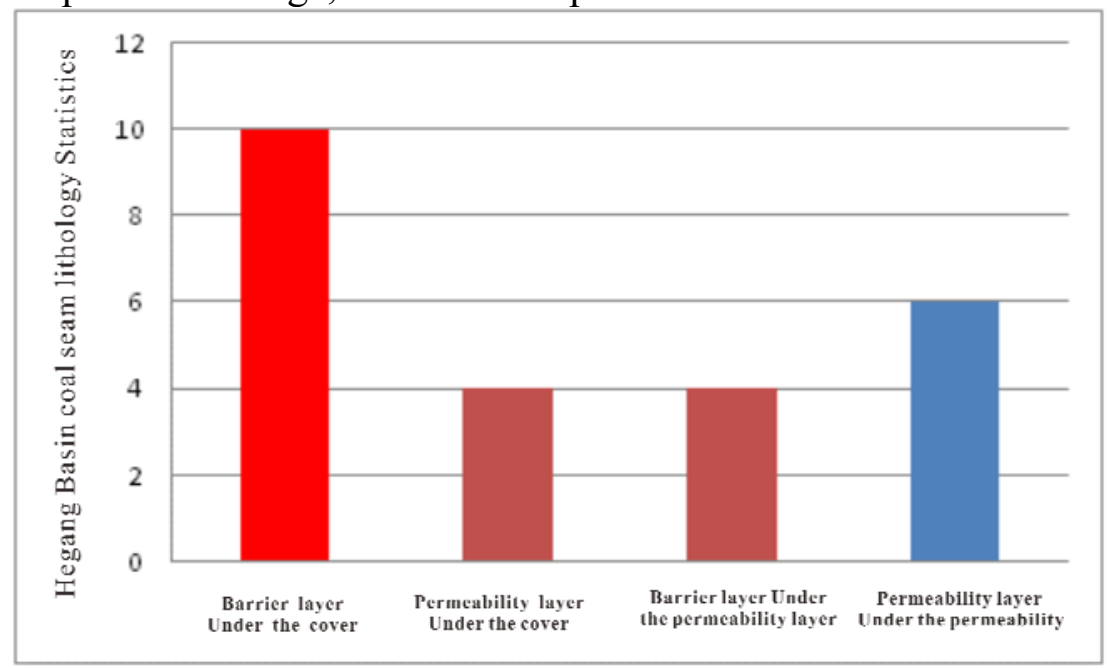

Fig. 2 static map of roof and base plate of coal seams in Hegang basin

\section{Conclusion}

1) Hegang basin is a monoclinal structure with northsouth trend and developed large and medium-sized fault in this area.

2) The total thickness of strata Chengzihe formation is $700 \sim 1310 \mathrm{~m}$, containing over 40 coal layers, including 36 exploiting and local exploiting layers. The coal cumulative thickness is between $30 \sim 70 \mathrm{~m}$, of which most are thick and medium thick coal layers and a few are especially thick.

3) The coal seams in Hegang mining area is mainly distributed in $1500 \mathrm{~m}$ under ground, but we always exploit in $900 \mathrm{~m}$ underground at present.

4) The coal macrolithotype in Hegang mining area is given priority to half light type, then the semidull coal and bright coal. The micropetrological unit of coal is mainly vitrinite, whose content is $52.2 \% \sim 82.3 \%$, then the semivitrinite content is $2.3 \% \sim 26.3 \%$, and the exinite content is $0.2 \% \sim 6.2 \%[4]$. In addition, its ash content is high to $15 \sim 30 \%[5]$.

5) The gas content between $500 \sim 1500 \mathrm{~m}$ in Hegang mining area is $1.6 \sim 19 \mathrm{~m}^{3} / \mathrm{t}$ and is high to $8.14 \sim 15.4 \mathrm{~m}^{3} / \mathrm{t}$ in Nanshan and Xinyi mining area[4].

6) According to statistic single well data in Hegang basin, we can see that the conditions for developing top cap bottom partition sealing type make up $42 \%$ of the total.Based on Comprehensive analysis these factors, the conditions for coalbed methane accumulation is superior to the south. It is better to explore the north of Hegang basin firstly.

\section{Acknowledgement}

China Postdoctoral Science Fund Project(2014M561324). 


\section{Reference}

[1] Xu Jianjun, Xu Yan-chao, Yan, Li-me,et.al. Research on the method of optimal PMU placement. International Journal of Online Engineering,v9, S7, p24-29, 2013

[2] Xu Jian-Jun, Y. Y. Zi., Numerical Modeling for Enhancement of Oil Recovery via Direct Current. International Journal of Applied Mathematics and Statistics, 2013，43 (13) : 318-326

[3] Longchao, Zhu Jianjun, Xu; Limei, Yan. Research on congestion elimination method of circuit overload and transmission congestion in the internet of things. Multimedia Tools and Applications, p 1-20, June 27, 2016

[4] Yan Limei, Zhu Yusong, Xu Jianjun,et.al. Transmission Lines Modeling Method Based on Fractional Order Calculus Theory. TRANSACTIONS OF CHINA ELECTROTECHNICAL SOCIETY, 2014 ,Vol.29,No. 9:260-268 (In Chinese)

[5] YAN Li-mei, CUI Jia, XU Jian-jun,et.al. Power system state estimation of quadrature Kalman filter based on PMU/SCADA measurements. Electric Machines and Control. 2014, Vol.18 No.6, 78-84. (In Chinese)

[6] YAN Limei,XIE Yibing, XU Jianjun, et.al. Improved Forward and Backward Substitution in Calculation of Power Distribution Network with Distributed Generation. JOURNAL OF XI'AN JIAOTONG UNIVERSITY,2013, Vol.47, No.6, p117-123. (In Chinese)

[7] Xu J.J., Gai D., Yan L.M. A NEW FAULT IDENTIFICATION AND DIAGNOSIS ON PUMP VALVES OF MEDICAL RECIPROCATING PUMPS. Basic \& Clinical Pharmacology \& Toxicology, 2016,118 (Suppl. 1), 38-38

[8] Xu Jianjun, Wang Bao'e, Yan Limei, Li Zhanping. The Strategy of the Smart Home Energy Optimization Control of the Hybrid Energy Coordinated Control. Transactions of China Electrotechnical Society, 2017, 32(12) 214-223. 